\title{
Spectrum of somatic mutations detected by targeted next-generation sequencing and their prognostic significance in adult patients with acute lymphoblastic leukemia
}

Juan Feng ${ }^{1,2+}$, Yan Li ${ }^{1+}$, Yujiao Jia ${ }^{1}$, Qiuyun Fang ${ }^{1}$, Xiaoyuan Gong ${ }^{1}$, Xiaobao Dong ${ }^{1}$, Kun Ru' ${ }^{1}$, Qinghua Li ${ }^{1}$, Xingli Zhao', Kaiqi Liu', Min Wang ${ }^{2}$, Zheng Tian², Yannan Jia ${ }^{1,2}$, Ying Wang ${ }^{1}$, Dong Lin', Hui Wei ${ }^{1,2}$, Kejing Tang ${ }^{2}$, Yingchang $\mathrm{Mi}^{1,2^{*}}$ and Jianxiang Wang ${ }^{1,2^{*}}$

\begin{abstract}
Target-specific next-generation sequencing technology was used to analyze 112 genes in adult patients with acute lymphoblastic leukemia (ALL). This sequencing mainly focused on the specific mutational hotspots. Among the 121 patients, 93 patients were B-ALL (76.9\%), and 28 patients (23.1\%) were T-ALL. Of the 121 patients, 110 (90.9\%) harbored at least one mutation. The five most frequently mutated genes in T-ALL are NOTCH1, JAK3, FBXW7, FAT1, and NRAS. In B-ALL, FAT1, SF1, CRLF2, TET2, and PTPN1 have higher incidence of mutations. Gene mutations are different between $\mathrm{Ph}^{+} \mathrm{ALL}$ and Ph ${ }^{-} \mathrm{ALL}$ patients. B-ALL patients with PTPN11 mutation and T-ALL patients with NOTCH1 and/or FBXW7 mutations showed better survival. But B-ALL with JAK1/JAK2 mutations showed worse survival. The results suggest that gene mutations exist in adult ALL patients universally, they are related with prognosis.
\end{abstract}

Keywords: Next-generation sequencing, Somatic mutations, Prognostic significance, Acute lymphoblastic leukemia

\section{To the editor}

Acute lymphoblastic leukemia (ALL) represents one of the most common malignant diseases of childhood, accounts for about $15 \sim 25 \%$ of acute leukemia in adults [1]. Adult ALL is generally characterized by diverse biological features, evident clinical heterogeneity, and worse prognosis than pediatric ALL [2]. With the development of genetics in ALL, several new subtypes of ALL and a series of prognostic-related molecular markers are put forward [3-5].

In the recent years, with the application of nextgeneration sequencing (NGS) technology, genomics has been extensively developed in both pediatric and adult ALL patients [6]. Samples and clinical information were

\footnotetext{
*Correspondence: miyingch@medmail.com.cn; wangjx@ihcams.ac.cn †Equal contributors

${ }^{1}$ Institute of Hematology and Blood Disease Hospital, Chinese Academy of Medical Sciences and Peking Union Medical College, Tianjin 300020, People's Republic of China

Full list of author information is available at the end of the article
}

collected from 121 adult ALL patients (Additional file 1:Table S1) with informed consent (ethical approval serial number is KT2015001-EC-1). These patients were from the Institute of Hematology and Blood Diseases Hospital, Chinese Academy of Medical Sciences. Target regions of 112 genes (Additional file 2: Table S2) were selected on the basis of known or suspected involvement in the pathogenesis of malignant hematologic disorder and were enriched and analyzed using a custom targeted NGS gene panel (Additional file 3). Then, the relationships between the mutations with higher incidence and the prognosis of ALL patients were analyzed (Additional file 4).

Of the 121 patients, a total of 110 patients $(90.9 \%)$ harbored at least one gene mutation with a median of 2 (0-7) mutations per sample. Thirty-nine patients (32.2\%) had more than 3 gene mutations (Additional file 5: Figure S1). Sixty genes were considered as possible pathogenic mutations when compared against multiple databases (Fig. 1a. The top 38 mutated genes were 

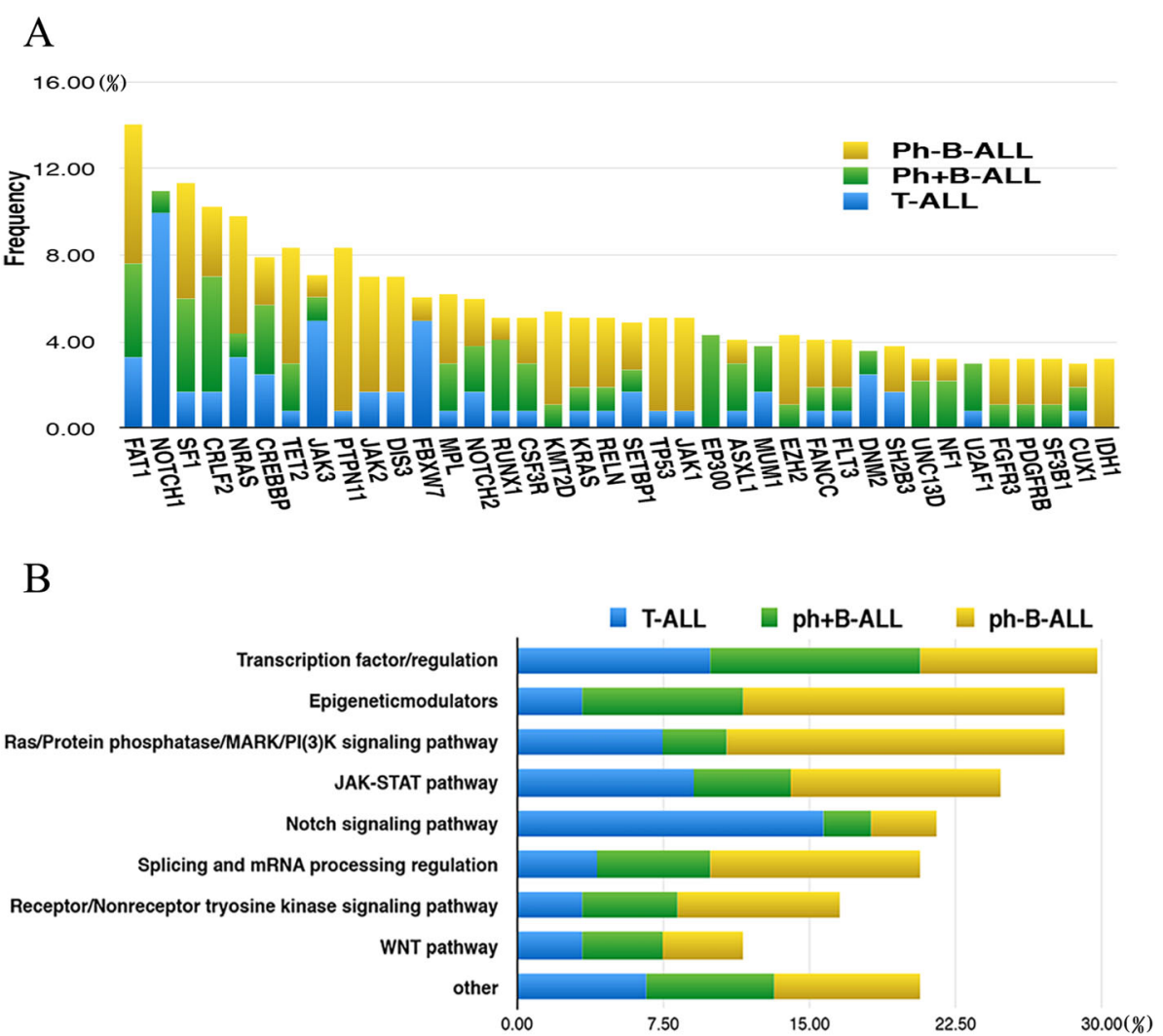

Fig. 1 Frequency of gene mutations and related signal pathways in ALL subtypes. a Frequency of the top 38 gene mutations in different ALL subtypes, which are shown in indicated colors. b Frequency of gene mutations involved in different functional pathways

listed). The five most frequently mutated genes were FAT1, NOTCH1, SF1, CRLF2, and NRAS (mutated in $>8 \%$ of the cases).

In 28 T-ALL cases, the most common mutated gene was NOTCH1, with a mutation rate of $39.3 \%(n=11)$, then JAK3, FBXW7, FAT1, NRAS, CREBBP, DNM2 (mutated in $>10 \%$ of the cases) (Additional file 6: Figure S2A). In B-ALL, FAT1 was the most accepted mutated gene (10.75\%), then SF1, CRLF2, TET2, PTPN11, NRAS, CREBBP, JAK2, DIS3, MPL, and KML2D (mutated in $>5 \%$ of the cases) (Additional file 6: Figure S2B). In $\mathrm{Ph}^{+}$ B-ALL, FAT1, CRLF2, SF1, EP300, and CREBBP genes mutated at higher incidences (Additional file 6: Figure S2C). However, PTPN11, SF1, TET2, NRAS, JAK2, DIS3, and FAT1 gene mutations occurred popularly in $\mathrm{Ph}^{-} \mathrm{B}-$ ALL (Additional file 6: Figure S2D).

The main signaling pathways involved in this targeted NGS gene panel were transcription factor/regulator, Ras/ protein phosphatase/MARK signaling pathway, JAK-STAT pathway, splicing and mRNA processing regulation, epigenetic modulators, and so on [7-9]. Frequencies of different signaling pathways involved are listed in Fig. 1b. Genes involved in these signaling pathways are listed in Additional file 7:Table S3.
In full cohort, the median overall survival (OS) was 34.88 (1.25-74.55) months, median relapse-free survival (RFS) was $30.85(0-73.55)$ months and 3-year OS and RFS rates were 49\%. In the full cohort, patients with PTPN11 mutation had a better prognosis compared with patients without PTPN11 mutation ( $p=0.040, p=0.047)$, and the patients with JAK2 mutation (7/117) had a worse prognosis compared with patients without JAK2 mutation $(p=0.031, p=0.018)$ (Additional file 8: Figure S3). B-ALL patients with PTPN11 mutation (7/93) had a better OS and RFS compared with those without PTPN11 mutation $(p=0.041, p=0.047)$ (Additional file 9: Figure $S 4$ ).

In T-ALL, patients with NOTCH1 and/or FBXW7 mutations had a better OS and RFS than patients without these mutations $(p=0.035, p=0.048)$ (Additional file 10: Figure S5).

Multivariate analysis of OS and RFS showed that the prognostic factors included JAK2 mutations (OS; $p=0.045$, RFS; $p=0.021)$ in the total adult ALL patients cohort. JAK1 mutations (OS; $p=0.004$, RFS; $p=0.005$ ) and JAK2 mutations (OS; $p=0.049$, RFS; $p$ $=0.044)$ for $\mathrm{Ph}^{-} \mathrm{B}$-ALL. The data was summarized in Table 1. 
Table 1 Univariate and multivariate analysis for OS and RFS

\begin{tabular}{|c|c|c|c|c|}
\hline & \multicolumn{2}{|l|}{ OS } & \multicolumn{2}{|l|}{ RFS } \\
\hline & $\overline{H R^{2}}$ & $P$ value & $\overline{H R^{2}}$ & $P$ value \\
\hline \multicolumn{5}{|l|}{ Univarite analysis (mut/all) } \\
\hline $\begin{array}{l}\text { PTPN11 mut; positive vs negative } \\
\text { in full cohort }(8 / 117)\end{array}$ & 0.043 & 0.040 & 0.044 & 0.047 \\
\hline In B-ALL (7/92) & 0.042 & 0.041 & 0.042 & 0.047 \\
\hline In $\mathrm{Ph}^{-} \mathrm{B}-\mathrm{ALL}(7 / 54)$ & 0.035 & 0.030 & 0.037 & 0.047 \\
\hline $\begin{array}{l}\text { JAK2 Mut; positive vs negative in } \\
\text { full cohort (7/117) }\end{array}$ & 3.02 & 0.031 & 3.309 & 0.018 \\
\hline In B-ALL (5/92) & 3.033 & 0.061 & 3.145 & 0.051 \\
\hline In $\mathrm{Ph}^{-} \mathrm{B}-\mathrm{ALL}(5 / 54)$ & 3.728 & 0.035 & 3.780 & 0.031 \\
\hline 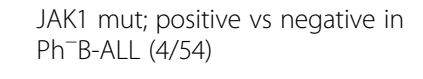 & 6.808 & 0.001 & 6.562 & 0.001 \\
\hline \multicolumn{5}{|c|}{ NOTCH1 and/or FBXW7 mut; positive vs negative } \\
\hline In T-ALL (12/25) & 0.204 & 0.035 & 0.223 & 0.048 \\
\hline \multicolumn{5}{|l|}{ Multivariate analysis } \\
\hline $\begin{array}{l}\text { PTPN11 mut; positive vs negative } \\
\text { in full cohort }\end{array}$ & 0.043 & 0.052 & 0.044 & 0.056 \\
\hline In B-ALL & 0.042 & 0.063 & 0.042 & 0.056 \\
\hline In $\mathrm{Ph}^{-} \mathrm{B}-\mathrm{ALL}$ & 0.035 & 0.178 & 0.037 & 0.212 \\
\hline $\begin{array}{l}\text { JAK2 mut; positive vs negative } \\
\text { in full cohort }\end{array}$ & 3.02 & 0.045 & 3.309 & 0.021 \\
\hline In $\mathrm{Ph}^{-} \mathrm{B}-\mathrm{ALL}$ & 3.728 & 0.049 & 3.780 & 0.044 \\
\hline $\begin{array}{l}\text { JAK1 mut; positive vs negative } \\
\text { in } \mathrm{Ph}^{-} \mathrm{B}-\mathrm{ALL}\end{array}$ & 6.808 & 0.004 & 6.562 & 0.005 \\
\hline \multicolumn{5}{|c|}{ NOTCH1 and/or FBXW7 mut; positive vs negative } \\
\hline In T-ALL & 0.204 & 0.055 & 0.223 & 0.069 \\
\hline
\end{tabular}

In summary, our study suggests that gene mutations exists in adult ALL patients universally, involving a variety of signaling pathways. The frequency and species are varied in different types of ALL. B-ALL patients were accompanied with PTPN11 mutation for good prognosis, while abnormal $J A K$ family often indicates poor prognosis. In T-ALL, mutation of NOTCH1 and/or FBXW7 indicates good prognosis.

\section{Additional files}

Additional file 1: Table S1. Demographic data, follow-up time, and ALL subtypes. (DOCX $52 \mathrm{~kb}$ )

Additional file 2: Table S2. 112 genes covered by a custom targeted NGS gene panel. (DOCX $94 \mathrm{~kb}$ )

Additional file 3: Supplementary: materials and methods. (DOCX $73 \mathrm{~kb}$ ) Additional file 4: Supplementary: statistical analysis. (DOCX $52 \mathrm{~kb}$ ) Additional file 5: Figure S1. Percentage of ALL patients with different somatic mutations. (TIF $1433 \mathrm{~kb}$ )

Additional file 6: Figure S2. Frequency of gene mutations in T-ALL (A), in B-ALL (B), in Ph+B-ALL (C), and in Ph-B-ALL (D). (DOCX 4090 kb)

Additional file 7: Table S3. Signal pathways affected and their frequency. (DOCX $70 \mathrm{~kb}$ )
Additional file 8: Figure S3. Probability of RFS or OS for total adult ALL patients with/without PTPN11 and JAK2 mutations. (TIF $4888 \mathrm{~kb}$ )

Additional file 9: Figure S4. Probability of RFS or OS in adult B-ALL patients with/without PTPN11 and JAK2 mutations. (TIF $4909 \mathrm{~kb}$ )

Additional file 10: Figure S5. Probability of RFS or OS in adult T-ALL patients with/without NOTCH1 and/or FBXW7 mutations. (TIF $3370 \mathrm{~kb}$ )

\section{Abbreviations}

ALL: Acute lymphoblastic leukemia; CR: Complete remission; NGS: Nextgeneration sequencing; OS: Overall survival; PCR: Polymerase chain reaction; RFS: Relapse-free survival; SNP: Single nucleotide polymorphisms; WBC: White blood cell

\section{Acknowledgements}

The authors thank Drs. Tian Yuan and Qi Zhang of MD Anderson Cancer Center for their valuable suggestions.

\section{Funding}

This study was supported by the National Science \& Technology Pillar Program (Grant no. 2014BAI09B12), Tianjin Major Research Program of Application Foundation and Advanced Technology (15JCZDJC36400), and Science and technology project of Tianjin (15ZXLCSY00010).

Availability of data and materials

Not applicable. All data used for conclusions are presented in the manuscript and figures.

\section{Authors' contributions}

YM and JW were responsible for the conception and design of the study. JF, YL, $Y J$, and XD participated in the development of methodology of the study. JF, $Y L, Y J, Q F, X G, Q L, X Z, K L, Z T$, and $K T$ contributed to the acquisition of data (acquired and managed patients' samples, provided facilities, etc.). JF, YL, KR, YJ, $\mathrm{QF}, \mathrm{XD}, \mathrm{YJ}, \mathrm{YW}$, and DL cooperated with the analysis and interpretation of data (e.g., statistical analysis, biostatistics, computational analysis). JF, YL, YM, JW, MW, and HW wrote, reviewed, and/or revised the manuscript. KR, QL, YJ, and XD contributed to administrative, technical, or material support (i.e., reporting or organizing data, constructing databases). YM supervised the study. All authors read and approved the final manuscript.

\section{Competing interests}

The authors declare that they have no competing interests.

\section{Consent for publication}

Not applicable.

\section{Ethics approval and consent to participate}

The study design was approved by Ethics Committee of Blood Diseases Hospital, Chinese Academy of Medical Sciences. The reference number is KT2015001-EC-1.

\section{Author details}

${ }^{1}$ Institute of Hematology and Blood Disease Hospital, Chinese Academy of Medical Sciences and Peking Union Medical College, Tianjin 300020, People's Republic of China. ${ }^{2}$ State Key Laboratory of Experimental Hematology, Tianjin 300020, People's Republic of China.

Received: 25 January 2017 Accepted: 23 February 2017

Published online: 28 February 2017

\section{References}

1. Mullighan CG, Goorha S, Radtke I, Miller CB, Coustan-Smith E, Dalton JD, et al. Genome-wide analysis of genetic alterations in acute lymphoblastic leukaemia. Nature. 2007;446:758-64.

2. Mullighan CG, Miller CB, Radtke I, Phillips LA, Dalton J, Ma J, et al. BCR-ABL1 lymphoblastic leukaemia is characterized by the deletion of Ikaros. Nature. 2008:453:110-4.

3. Fransecky L, Neumann M, Heesch S, Schlee C, Ortiz-Tanchez J, et al. Silencing of GATA3 defines a novel stem cell-like subgroup of ETP-ALL. J Hematol Oncol. 2016;9(1):95. 
4. Jain N, Lamb AV, O'Brien S, Ravandi F, Konopleva M, et al. Early T-cell precursor acute lymphoblastic leukemia/lymphoma (ETP-ALL/LBL) in adolescents and adults: a high-risk subtype. Blood. 2016;127(15):1863-9.

5. Xu N, Li YL, Li X, Zhou X, Cao R, et al. Correlation between deletion of the CDKN2 gene and tyrosine kinase inhibitor resistance in adult Philadelphia chromosome-positive acute lymphoblastic leukemia. J Hematol Oncol. 2016;9:40.

6. Roberts KG, Mullighan CG. Genomics in acute lymphoblastic leukaemia: insights and treatment implications. Nat Rev Clin Oncol. 2015;12:344-57.

7. Kandoth C, McLellan MD, Vandin F, Ye K, Niu B, Lu C, et al. Mutational landscape and significance across 12 major cancer types. Nature. 2013; 502:333-9.

8. Neumann M, Vosberg S, Schlee C, Heesch S, Schwartz S, Gökbuget N, et al. Mutational spectrum of adult T-ALL. Oncotarget. 2015;6:2754-66.

9. Haferlach T, Nagata Y, Grossmann V, Okuno Y, Bacher U, Nagae G, et al. Landscape of genetic lesions in 944 patients with myelodysplastic syndromes. Leukemia. 2014;28:241-7.

Submit your next manuscript to BioMed Central and we will help you at every step:

- We accept pre-submission inquiries

- Our selector tool helps you to find the most relevant journal

- We provide round the clock customer support

- Convenient online submission

- Thorough peer review

- Inclusion in PubMed and all major indexing services

- Maximum visibility for your research

Submit your manuscript at www.biomedcentral.com/submit
Biomed Central 